\title{
Failure Analysis of Pivot Housing in Wag-09 Locomotive
}

\section{Sneha V Pawade*}

Research Scholar, Department of Mechanical Engineering G.H. Raisoni College of Engineering, Nagpur-16, India

\begin{abstract}
Railway system in India plays a vital role in transportation. The demand of prolong service life and reliability of the various component are always considered as critical issue. The component of the study has been obtained from the Central Railway, Electric Loco Shed Ajani Nagpur M.S India. In the present study the failure of one of the components of traction link (Pivot Housing) is carefully investigated. This paper presents theoretical and finite element analysis (FEA) results for the pivot housing assembly which predicts the failure load and determines ultimate failure strength. A significant result of these studies includes increasing the bending strength of Pivot Housing. The measured stresses were in good agreement with theoretical results. To get the additional insight, finite element analysis results are presented and compared to both.
\end{abstract}

Keywords: FEA; Failure analysis; Pivot housing; WAG-9

\section{Introduction}

WAG-9 is the name of a type of electric locomotive used in India shown in Figure 1. This six axle loco is designed to give a starting tractive effort of $460 \mathrm{KN}$ and maximum braking effort of $260 \mathrm{KN}$. Rated 6000 HP. Pivot Housing is an assembly used in Indian Railway's loco WAG-9/WAP-7as a main power transmitting unit as shown in Figure 2 and 3. This assembly connects the superstructure (under frame) and bogies. The centre-pivot of the bogie is used to transmit the tractive and braking forces. It has also to bear the body weight. As this assembly is main power transmitting unit, numerous types of forces acts on the assembly which may be static or dynamic. Pivot assembly comprises of various components such as traction link, safety cables, chain, link rod, pivot housing, ring, retaining plates, and locking tab $[1,2]$.

The loco was manufactured initially in Switzerland. In 1998 the technology is adapted by Indian government and then the manufacturing was started in India. This assembly is used to connect the central assembly of the transformer and two loco bogies. Failure of pivot housing of this assembly is discussed in detail in this investigation.

In this assembly the pivot housing is situated at each end of the link rod.

\section{Methodology}

\section{Data collection and visual inspection}

As per the maintenance record [2] of Loco Shed that there is early

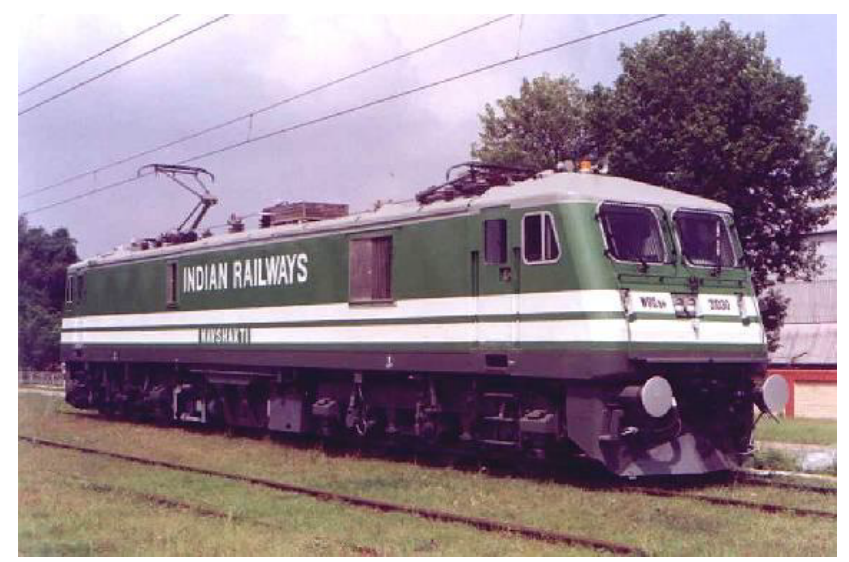

Figure 1: WAG-9 Locomotive. premature failure of Pivot Housing. Following are the observations on failed pivot housing:

1. The pivot housing usually fails during running condition after certain period.

2. $100 \%$ crack at the neck region of flange plate.

3. The initiation of crack begins near the corner of neck region which progresses and breaks the flange plate.

\section{Specification of pivot housing}

Dimensional details of pivot housing are as follows in Table 1 which is mentioned in the input data [3].

This Pivot Housing material is made up of cast steel (DIN 17182 GS 20Mn 5) [2]. In this proposed study the stress analysis of the crack

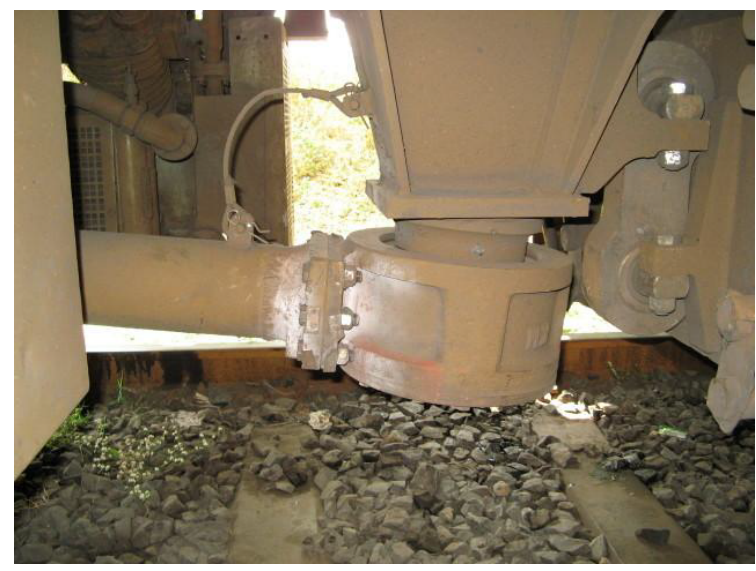

Figure 2: Pivot Housing Assembly.

*Corresponding author: Sneha V Pawade, Research Scholar, Department of Mechanical Engineering G.H. Raisoni College of Engineering, Nagpur-16, India, Tel: +91 7104-232560; E-mail: snehapawade@gmail.com

Received May 01, 2014; Accepted May 03, 2014; Published May 13, 2014

Citation: Pawade SV (2014) Failure Analysis of Pivot Housing in Wag-09 Locomotive. J Appl Mech Eng 3: 144. doi:10.4172/2168-9873.1000144

Copyright: (c) 2014 Pawade SV. This is an open-access article distributed under the terms of the Creative Commons Attribution License, which permits unrestricted use, distribution, and reproduction in any medium, provided the original author and source are credited. 


\begin{tabular}{|l|l|}
\hline Particulars & Pivot Housing \\
\hline Outside diameter (Do) $(\mathrm{mm})$ & 320 \\
\hline Inside diameter $(\mathrm{Di})(\mathrm{mm})$ & 250 \\
\hline Weight $(\mathrm{W})(\mathrm{kg})$ & 31 \\
\hline
\end{tabular}

Table 1: Dimensional details of pivot housing.

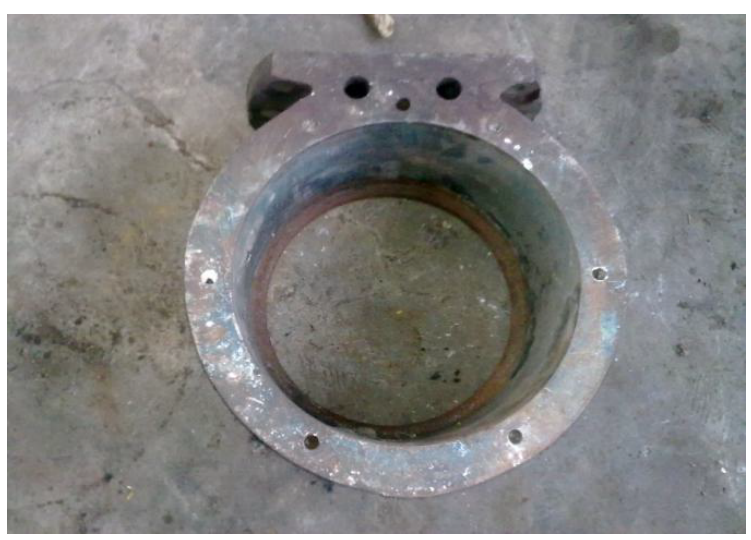

Figure 3: Pivot Housing.

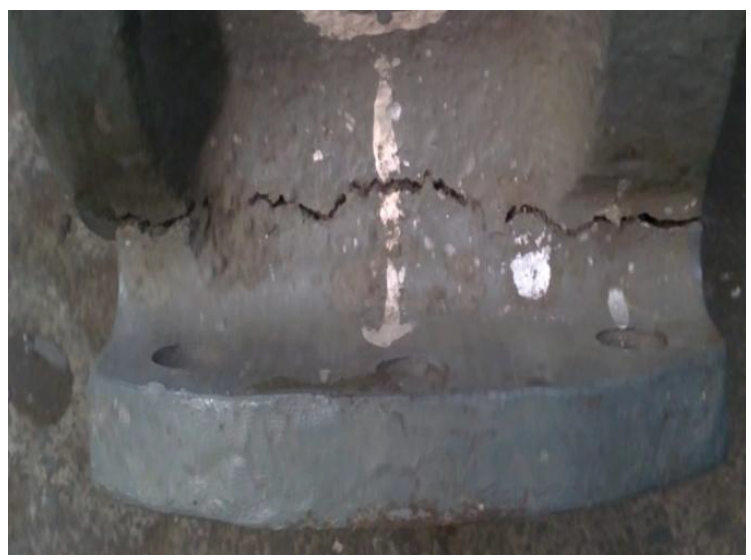

Figure 4: Failure Component.

formed at curvature of the flange region (Figure 4) of the Pivot Housing is discussed in details.

\section{Results and Discussion}

\section{Therotical analysis of forces acting on pivot housing}

Schematic diagram of load distribution on Pivot Housing is shown in Figure 5

Pivot Housing is subjected to action of force, which can be conveniently resolved into three components:-

- Tangential (Fz) (centrifugal load)

- Radial (Fx) (pulling load)

- Axial (Fy) (cyclic load) [4].

\section{CASE-I: Load Analysis for Loco Moving on Straight Path}

The overall load of about 123 tonne of loco is acted over the Pivot Housing assembly. The schematic diagram of Figure 5 shows the load distribution over the pivot Housing. Using various load acted upon the pivot Housing assembly when loco is moving on straight path are as given below.

1. Total weight of loco $=123 \mathrm{~T}$

2. Speed $V \max =100 \mathrm{~km} / \mathrm{hr}$

3. Speed $\mathrm{Vmin}=50 \mathrm{~km} / \mathrm{hr}$

4. Radius of curvature $=292 \mathrm{~m}$

5. Under weight (bogie weight) $=20$ ton

6. Cross sectional area of Flange $=7800 \mathrm{~mm}^{2}$

7. Maximum Pulling force $=24$ Tonne

8. Minimum pulling force $=6$ Tonne [2]

CAST STEEL DIN 17182 GS20Mn5, following properties are considered $[5,6]$.

> Ultimate Tensile strength $=550 \mathrm{MPa}$

> Yield strength $=300 \mathrm{MPa}$

$>$ Endurance limit for cast steel:-

$\mathrm{Fe}=0.4 \mathrm{fu}$

$=0.4 \times 550=220 \mathrm{mpa}$

$>$ Endurance Strength $\left(\mathrm{F}_{\mathrm{e}}\right)=220 \mathrm{Mpa}$

Where $\mathrm{F}_{\mathrm{e}}$-endurance stress

$\mathrm{F}_{\mathrm{u}}$-Ultimate tensile stress

The load 24 Tonne is acting on a single pivot Housing. As there are two Housings, net load is 48 Tonne. This load is distributed over entire pivot Housing assembly. Following assumptions were made for simplification [7].

$>$ The rails are smooth and there are no geometrical irregularities.

$>$ The loading is static.

$>$ Impact load during operation are neglected.

$>$ All other kind of load than mentioned in calculations is neglected.

By applying the Soderberg Method for the combination of stresses, using surface finish factor and stress concentration factor, yield stresses

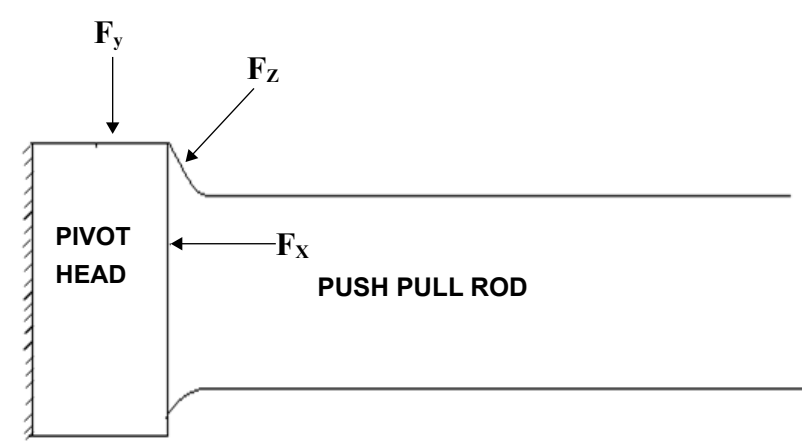

Figure 5: Load Distribution on Pivot Housing. 


\begin{tabular}{|l|l|l|}
\hline Particulars & Unit & Pivot Housing \\
\hline Fatigue stress concentration factor $(\mathrm{k})$ & - & 1.35 \\
\hline Factor of safety & - & 2 \\
\hline Surface finish factor $(\mathrm{ksur})$ & - & 0.85 \\
\hline Size factor $\left(\mathrm{k}_{\mathrm{sz}}\right)$ & - & 0.84 \\
\hline Load $(\mathrm{w})$ & $\mathrm{N}$ & 235440 \\
\hline Yield stress $\left(\mathrm{f}_{\mathrm{s}}\right)$ & $\mathrm{N} / \mathrm{mm}^{2}$ & 164.72 \\
\hline
\end{tabular}

Table 2: Analytical results of pivot Housing for the loco at straight path.
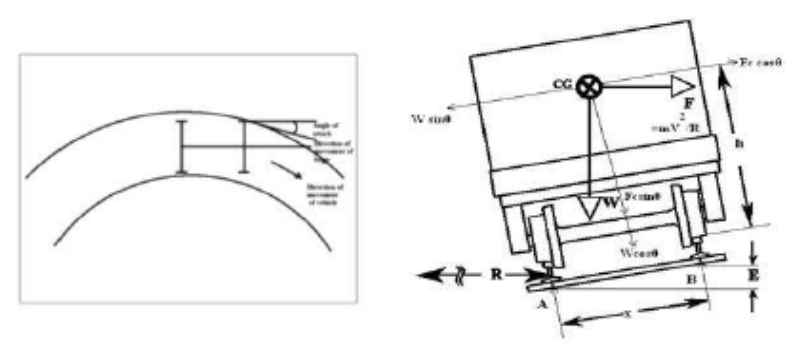

Figure 6: Loco at Radius of Curvature.

and other design parameters were calculated for the case of loading on straight path and are shown in Table 2.

Soderberg Equation- (for ductile material) [6]

$\frac{1}{f_{s}}=\frac{f m}{f y}+\frac{f_{v} \times K}{f_{e a} \times k_{s u r} \times k_{s z}}$

Where,

$\mathrm{f}_{\mathrm{e}}=$ Endurance Limit

$\mathrm{F}_{\mathrm{u}}=$ Ultimate stress (tensile or compressive)

f.s =Factor of safety

$\mathrm{f}_{\mathrm{m}}=$ Mean stress (tensile or compressive)

$\mathrm{f}_{\mathrm{y}}=$ Yield stress

$\mathrm{f}_{\mathrm{v}}=$ Variable stress

$\mathrm{k}=$ Fatigue stress concentration factor

$\mathrm{k}_{\mathrm{sur}}=$ Surface finish factor

$\mathrm{k}_{\mathrm{sz}}=$ Size factor

\section{CASE-II: Load analysis for loco moving on the curved path}

While moving on the curved path the loco is subjected to additional load because of centrifugal force. The Figure 6 shows the load when the loco is moving on curved path. Following are the details for calculation of the load.

1. The loco speed is $100 \mathrm{~km} / \mathrm{hr}$.

2. The radius of curvature is $292 \mathrm{~m}$, which is the minimum recommended radius.

The resultant stress calculated analytically is found to be $(164.72+83.48)=248 \mathrm{~N} / \mathrm{mm}^{2}$. From Table 2 and 3, it is clear that the stress is exceeding the endurance stress $220 \mathrm{~N} / \mathrm{mm}^{2}$ which is exceeding the endurance stress $220 \mathrm{~N} / \mathrm{mm}^{2}$.

Finite Element Analysis By Ansys-12: Using the technical specification of pivot housing the Finite Element analysis was carried out in Ansys 12.0. A higher order 3-D, 10-node element having three degrees of freedom at each node: translations in the nodal $\mathrm{x}, \mathrm{y}$, and $\mathrm{z}$ directions SOLID92 was used [8]. Theoretical analysis of pivot housing carried out in earlier section and results obtained for maximum yield stress $\left(\mathrm{F}_{\mathrm{y}}\right)$ are compared by using Finite elemental analysis.

The Figure 7 depicts the loading and boundary condition.

A 3D FE mesh was developed to study this problem and obtain the stress distribution in the part. Figure 8 shows 3D FE meshes of the node [9].

As clearly seen from Figure 9, the maximum stress value is obtained in the flange region and minimum stress value is obtained in the fixed pivot region. Table 4 shows the comparison of theoretical analysis \& FE analysis.

The entire result and discussion thus can be complied as follows.

1. Theoretical equivalent stress value $\left(F_{y}\right)$ is almost similar to that of the value calculated using Finite element analysis software. Hence it can be said that theoretical equivalent stress value $\left(\mathrm{F}_{\mathrm{y}}\right)$ is validated using smart design tool of finite element analysis.

2. Allowable stress value is $220 \mathrm{~N} / \mathrm{mm}^{2}$ [6]. As per design

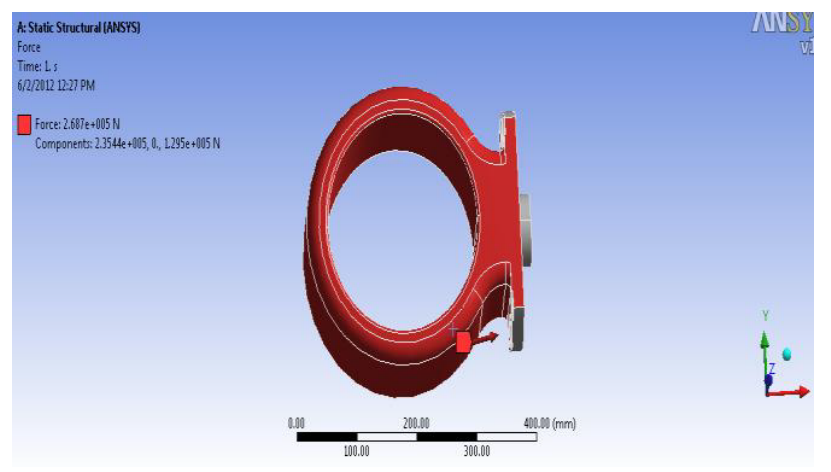

Figure 7: Loading and Boundary Condition.

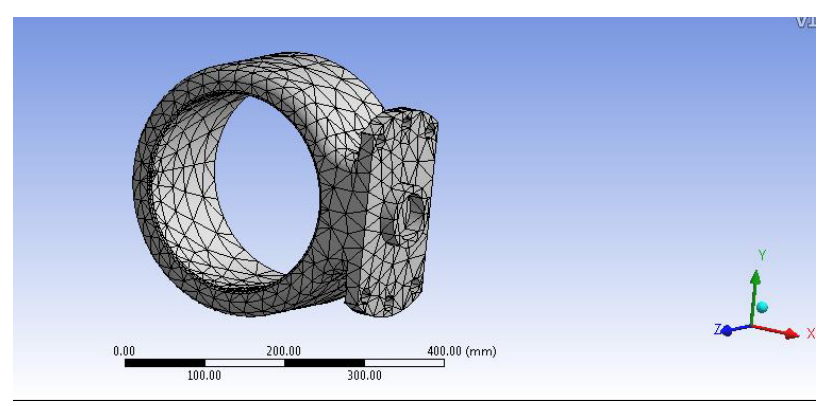

Figure 8: Mesh for the Pivot Housing.

\begin{tabular}{|l|l|l|}
\hline Particulars & Unit & Pivot Housing \\
\hline Load $(w)\left(F_{z}\right)$ & $N$ & 129500 \\
\hline Yield Stress $(F y)$ & $\mathrm{N} / \mathrm{mm}^{2}$ & 83.48 \\
\hline
\end{tabular}

Table 3: Analytical results of pivot Housing for loco at curved path.

\begin{tabular}{|l|l|l|}
\hline Parameters & Analytical & ANSYS \\
\hline Equivalent stress $\left(\mathrm{N} / \mathrm{mm}^{2}\right)(\mathrm{Fy})$ & 248 & 244.6 \\
\hline
\end{tabular}

Table 4: Comparison of Analytical and ANSYS calculation. 


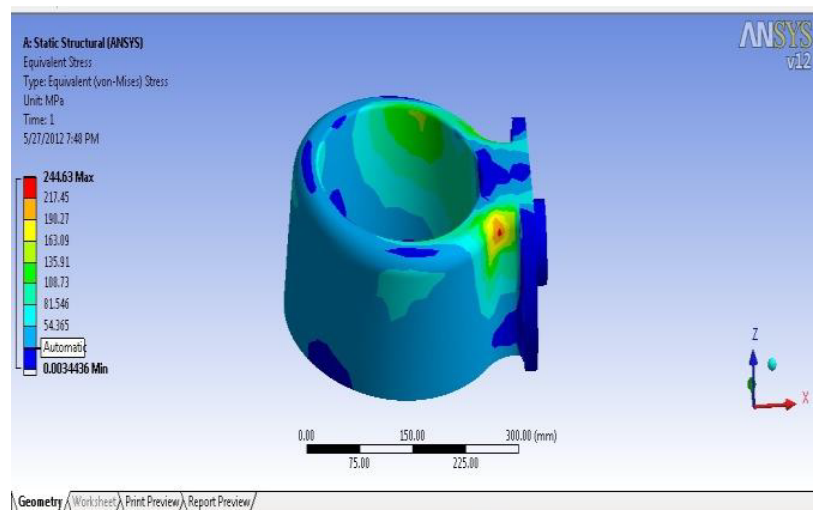

Figure 9: Equivalent Stress for Pivot Housing.

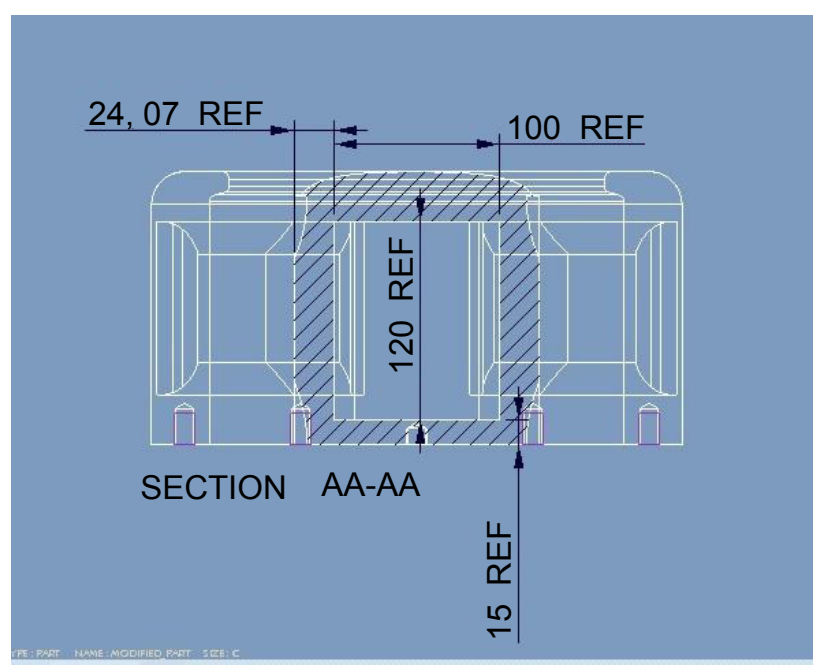

Figure 10: Original Thickness of Pivot Housing.

\begin{tabular}{|l|c|c|c|c|c|}
\hline Results & $\begin{array}{c}\text { Design } \\
\text { Changes }\end{array}$ & Thickness & Area & $\begin{array}{c}\text { Endurance } \\
\text { Limit (Mpa) }\end{array}$ & $\begin{array}{c}\text { Max Stress } \\
\text { (Mpa) }\end{array}$ \\
\hline Iteration No. 1 & Original 120×100 & $15 \times 24$ & 7800 & 220 & 248 \\
\hline Iteration No. 2 & $100 \times 90$ & $25 \times 29$ & 10800 & 220 & 179.3 \\
\hline Iteration No. 3 & $80 \times 80$ & $35 \times 34$ & 13400 & 220 & 145.5 \\
\hline Iteration No. 4 & $60 \times 70$ & $45 \times 39$ & 15600 & 220 & 150.3 \\
\hline Iteration No. 5 & $40 \times 60$ & $55 \times 45$ & 17400 & 220 & 111.22 \\
\hline
\end{tabular}

Table 5: Suggested Solution By Changing Thickness of Pivot Housing.

calculations this limit is exceeding to $248 \mathrm{~N} / \mathrm{mm}^{2}$. Therefore the need of redesign is justified.

Suggested redesigned model: On the basis of the above conclusions, redesigning is carried out and related details are as follows

Cross section at neck region: Figure 10 shows sectional view indicating original thickness of forged pivot housing.

$>$ In existing model, outer rectangular dimension is $132 \times 150 \mathrm{~mm}$ and inner rectangular dimension is $120 \times 100 \mathrm{~mm}$ which shows the thickness of $15 \times 24 \mathrm{~mm}$.

$>$ Cross-sectional area of existing model $=[(132 \times 150)-(120 \times 100)]$ $=7800 \mathrm{~mm}^{2}$

Table 5 indicates various iterations carried out for redesigning purpose. The different combinations of length and thickness of pivot are considered in these iterations.

Figure 11 and 12 shows sectional view of the original pivot housing and Suggested Redesigned pivot housing. Amongst the different iterations, Iteration No 3 has shown optimized results. Hence further analysis of this redesigned model was carried out.

Analysis for suggested redesigned model: The suggested model contains same material properties, loading condition. The boundary condition is kept same as used in the existing model that is flange of pivot is kept fixed.

Equivalent von- misses stress: The maximum stress value is found in the flange region. The stress value calculated analytically is $145.5 \mathrm{Mpa}$ and using ansys is $161.41 \mathrm{Mpa}$ and minimum stress value is $0.4768 \mathrm{Mpa}$ which is obtained in the fixed pivot region. The computed stress value 161.41 Mpa is highly acceptable because it is less than the maximum required stress limits $220 \mathrm{Mpa}$.

\section{Conclusions and Further Suggestions}

The loco has to travel on the rails which have the joints and local irregularities which bring the impact loads. Requirement of the design for moving the loco on the curved path is also very critical. The same was validated using FE Analysis. The FE analysis suggests the maximum yield stress of about $248 \mathrm{~N} / \mathrm{mm}^{2}$ while moving on the critical curvatures. This is more as that of allowable stress of $220 \mathrm{~N} / \mathrm{mm}^{2}$. The bending stresses may initiate a failure which is further enhance and

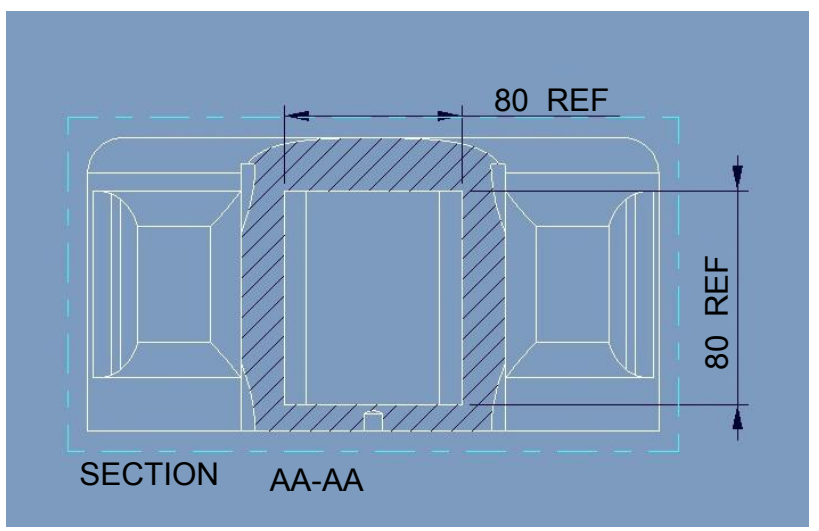

Figure 11: Suggested redesigned $(80 \times 80) \mathrm{mm}$ Dimension.

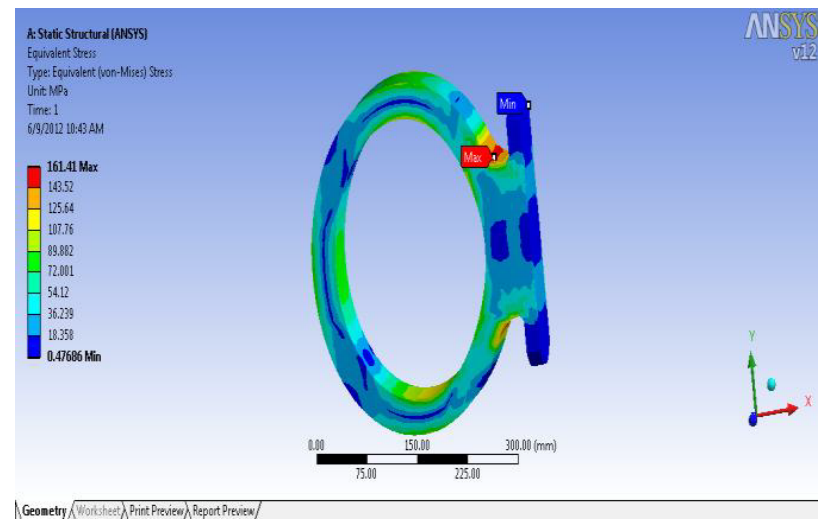

Figure 12: Equivalent Stress of Optimized Model. 
aggregated because of stress concentration at the failure region and nature of loading.

Redesigning of Pivot Housing was carried out in this work.

Following conclusion were drawn on the basis of modeling (PRO-E) and Analysis (ANSYS) SOFTWARE. Thickness $f$ the neck region was redesigned (Table 5).

On the basis of five iterations, thickness was optimized.

$>$ It is concluded that the following dimensions allowed the maximum possible stress with minimum weight of Pivot Housing.

\section{Acknowledgement}

The authors gratefully acknowledge Central Railway Electric Loco Shed Ajani, Nagpur (M.S) India, for providing necessary support in order to conduct the failure analysis.

\section{References}

1. Liu ZX, Gu HC (2000) Failure Modes and Materials Performance of railway Wheels, Journal of Materials Engineering and Performance 9: 580-584.

2. Indian Railways Wag-9 Maintenance Repair Manual, Ajni Electric Loco Shed.

3. Indian railways Pivot Housing drawing, Ajni, Nagpur.

4. Singer FL (1975) Engineering Mechanics, Statics And Dynamics, Tata McGraw Hill publication.

5. PSG College of technology (1966) Design data book, Coimbatore publication.

6. Khurmi RS, Gupta JK (2005) A textbook of Machine Design Eurasia Publishing House, India.

7. Kumbhalkar MA (2011) Failure Analysis of Inner Suspension Spring of Railway Engine: A Case Study.

8. Infantea V, Brancoa CM, Britoa AS, Morgadob TL (2003) A failure analysis study of cast steel railway Couplings used for coal transportation, Engineering Failure Analysis 10: 475-489.

9. Ansys Mechanical User Guide. 